\title{
PROBLEMS OF DETERMINATION OF WELDING ANGULAR DISTORTIONS OF T - FILLET JOINTS IN SHIP HULL STRUCTURES
}

Janusz Kozak, Prof.

Jakub Kowalski, M.Sc.

Gdańsk Univeristy of Technology, Poland

\begin{abstract}
Ship hull structure elements are usually joined by welding. Welding distortions may cause many problems during manufacturing process. In the literature a wide spectrum of suggestions has been proposed for correct estimation of welding deformation, particularly angular ones, in the fillet welded T-joints. In this work a verification of certain methods selected from the literature is presented basing upon the results of the laboratory measurements. To this end, values determined on the basis of engineering hypotheses have been compared with those obtained from the laboratory tests.
\end{abstract}

Keywords: welding deformations, ship structure welding, angular distortions in welded T-joints

\section{INTRODUCTION}

During building processes of ship's metal hull joints of structural elements are generally made by means of welding techniques. As a result of using the welding processes, in the area of welded joints and neighbouring structures, arise stresses which - depending on stiffness of the object in question manifest themselves in the form of deformations of various kinds. They often occur in an uncontrollable way causing many troubles during production, hence they significantly influence manufacturing accuracy of products.

Deformations which exceed allowable values, may cause troubles in assembling hull's sections or make the operation completely unfeasible (Fig. 1), unfavourably influence further manufacturing processes and final quality of a product, lower its usage and aesthetic features.

Welding deformations are strictly associated with welding process hence they influence dimensional deviations of structure after welding. Excessive deformations which exceed permissible limits, require to be removed by straightening or in extremely unfavourable cases a new structure is to be produced, which extends time of manufacturing and rises its cost.

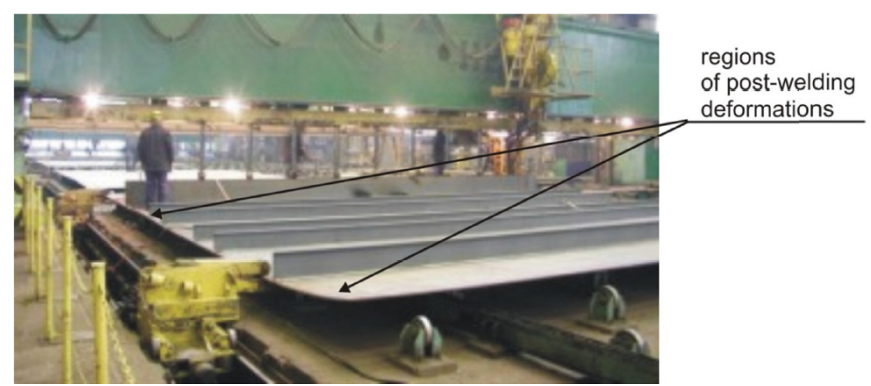

Fig. 1. Welding deformations of a plate section

It should be stressed that already quality of structural design may to a large extent decide on susceptibility of the structure to deforming during production processes. Therefore already in the structural design stage, should be undertaken appropriate measures in order to minimize expected consequences in the area of welding deformations. In the stage of preparation of production process the principle of applying every possible preventing measures against deformations should be used 
instead of assuming their removing in general after production of structure. As proved in practice, sum of effects resulting from application of many, rather tiny, preventing measures makes it possible to manufacture whole structure at maintaining the principle of minimizing production troubles and reducing the straightening operation to a "cosmetic" treatment only. Therefore capability of the predicting, estimating and preventing of welding distortions is an important tool in production of a thin - walled metal structure such as a floating object's hull.

There are engineering ways to minimize quantity of deformations and to remove them. Among them the following may be for instance numbered: correct sequence of assembling and welding operations, application of initial deformations, rigid clamping the elements during welding, loading the elements by external forces to introduce a deflection opposite to that expected. In any case the prediction and compensation of deformations aiming at application of initial deformations require knowledge and skill in determining their form and quantity.

\section{ANGULAR DEFORMATIONS IN WELDED T- JOINT}

Present state of the theory in the field of calculation of welding deformations makes it possible to precisely analyse the issue in order to preliminarily determine deformations and select production methods and means for conducting manufacturing process. During preparation of constructional and technological assumptions appropriate calculation methods should be used, including computer programs. The only problem consists in complexity of computational process. In spite of the fact that the physical background of welding processes has been already formulated and the formulas mainly empirical - for estimating the deformations, have been elaborated, impact of many structural and technological factors results in that to keep full control over deformations is very difficult.

The formulas met in the literature often give, especially in case of thin-walled structures such as contemporary ship's hull, results which significantly differ from actual ones. Therefore to verify such data is necessary.

The issue of excessive welding deformations arises especially in manufacturing ship hull structures with thin plates less than $10 \mathrm{~mm}$ in thickness. The index should be taken only as approximate one because assessment criteria may depend on requirements put for ready-welded structure, as for instance to get relatively small welding distortions is required to ensure appropriate conditions for assembling and welding propulsion machinery foundations /welded of thick plates/, and - in contrary - large deformations of certain partition walls in superstructure may be tolerated if only they are boarded on both sides and do not participate in carrying local loads.

Since over two decades the Finite Element Analysis (FEA) and Finite Element Method (FEM) have been applied to determination of stress distribution field during welding process. Achieving correct results is complicated by such problems as: material properties varying during welding process, high temperature gradients, stress and strain development both in the time and space coordinates domain, large deformations of thin-walled structures and phase and structural transitions in material. Majority of presently proposed simulation methods for welding processes is based on the assumption of a small deformation and is limited only to simple structures and shapes (e.g. butt welds) or is focused only on heat affected zone not taking into account surrounding structure. Analysis of small deformations assumes infinitesimal displacements and loads applied to a structure of non-deformed geometry. Examples of such simulations are given in [6] and [9] where impact of a few parameters on welding process model, is presented.

In the amount of welded joints in ship hull structure, fillet welds take a large part. In this case numerical calculations are complicated by the fact that the joints are made in the form of two welds laid often non-simultaneously [3].

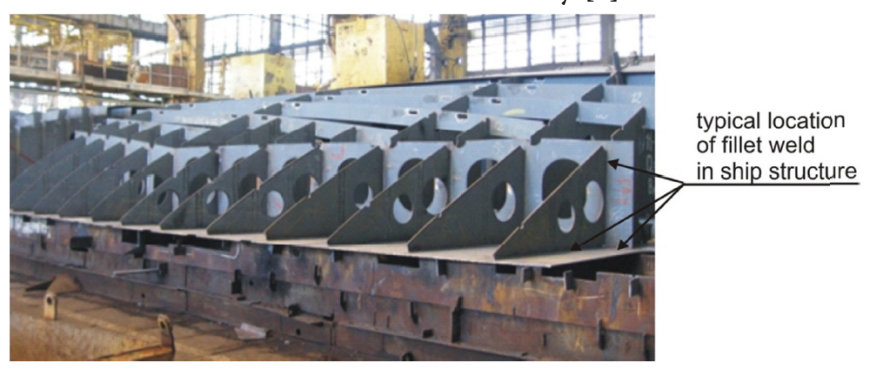

Fig. 2. View of a ship performing transport task in stormy weather [33]

In the works [10][7][8] N. O. Okerblom has given the theoretical background for determining welding stresses and strains. In analysis process changes in plastic deformations are considered in every phase of heat cycle to which a given area of cross-section of an element under welding is subjected, as well as the deformations are simulated during whole heat cycle. However to apply the so proposed approach to calculation of angular distortions in T-joint is difficult.

\section{EXPERIMENTAL DETERMINATION OF WELDING ANGULAR DEFORMATIONS OF FILLET JOINT IN SHIP HULL STRUCTURE} [1]

For determination of a typical angular deformation in welded T-joint it was arranged to produce a series of such joints with simultaneous recording process parameters and occurring deformations. It was assumed that the designed joint has been a modification of a typical ship structure joint having weld dimensions in accordance with PRS rules, Part II - Hull [13]. The dimension was 3,5 [mm]. The experiment consisted in determination of angular deformation in the joint both during and after welding a bulb profile stiffener to a plate. The specimens were made of ship structural steel of A grade. The tests were carried out with 5 specimens.

Fig. 3 highlights the concept of test stand, testing and measurement method as well as tested model dimensions. 


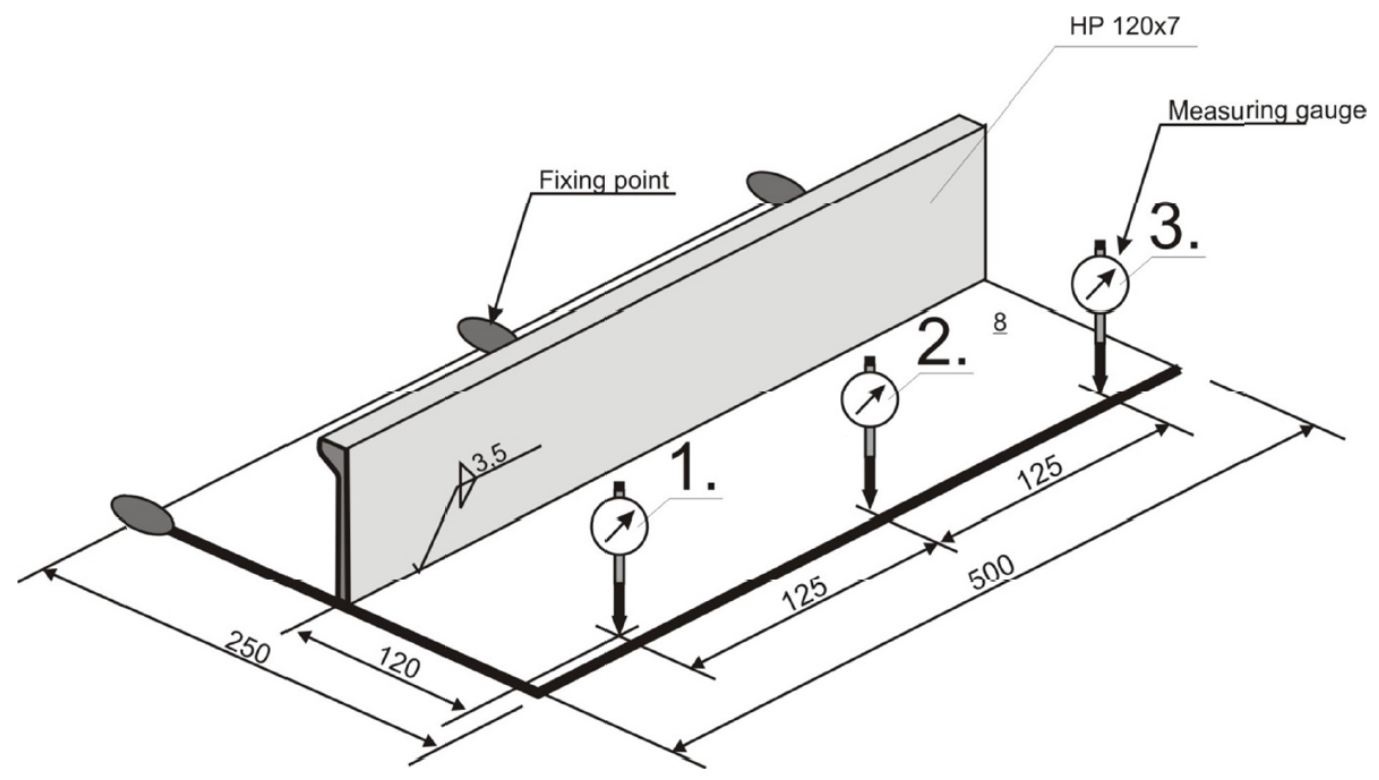

Fig.3. Schematic diagram of tested model and test stand

To eliminate bending deflection during welding positional welds were applied between the plate and stiffener and the specimen was fastened to the welding bench(Fig.4). The welding process was carried out according to the welding procedure (WPS) for the welding method 136 - FCAW (Flux-Cored Arc Welding), approved by PRS.

Procedure of joint preparation, geometry of welds, sequence of runs and welding process parameters are presented in Tab. 1.

Tab. 1 Welding Procedure Specification (WPS)
During welding all the process parameters were recorded: arc voltage, welding current intensity and weld laying speed. During laboratory tests the T464ZPMIH5 welding wire of the characteristics: $460 \mathrm{MPa}$ minimum yield strength and 20\% minimum elongation, was used.

Angular deformation was measured by using M2 TOP dial gauges (Fig. 3 and 4).

After manufacturing the welds their size were measured and for further analysis were taken only the specimens whose welds showed dimensions complying with the assumed value of $3,5[\mathrm{~mm}]$. Results of the performed tests are given in Tab. 2 .

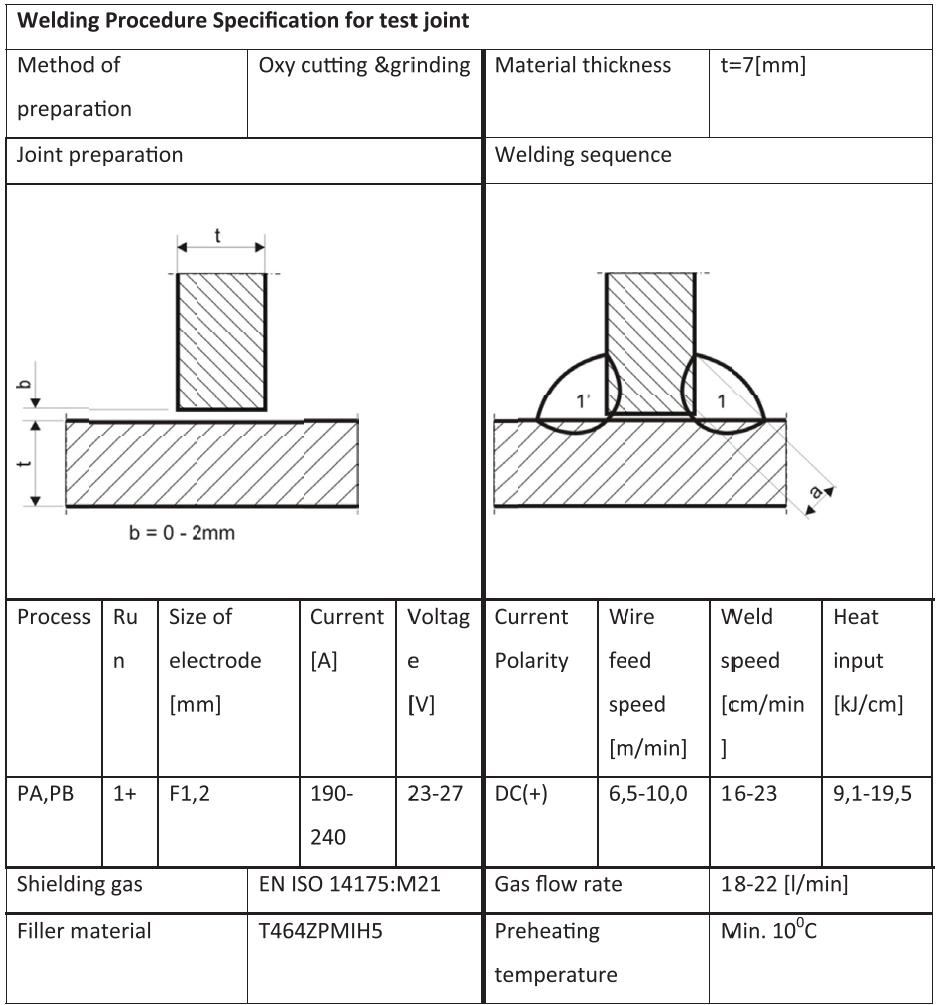
Tab. 2. Results of the performed tests [1]

\begin{tabular}{|c|c|c|c|c|c|c|c|}
\hline \multirow[b]{2}{*}{ 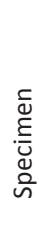 } & \multirow[b]{2}{*}{$\begin{array}{l}5 \\
\frac{1}{2} \\
40 \\
0 \\
\dot{0}\end{array}$} & \multirow[b]{2}{*}{ 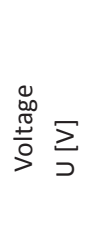 } & \multirow{2}{*}{ 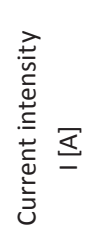 } & \multirow[b]{2}{*}{ 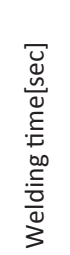 } & \multicolumn{3}{|c|}{ Displacements } \\
\hline & & & & & 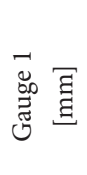 & 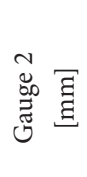 & 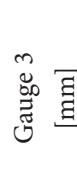 \\
\hline \multirow[t]{2}{*}{1} & 1 & 27,5 & 184 & 33,2 & 1,76 & 1,73 & 1,21 \\
\hline & 2 & 27,7 & 175 & 20,1 & 4,85 & 5,71 & 4,99 \\
\hline \multirow[t]{2}{*}{2} & 1 & 26,7 & 172 & 34,9 & 1,76 & 1,60 & 1,99 \\
\hline & 2 & 26,5 & 173 & 38,5 & 4,87 & 4,90 & 5,57 \\
\hline \multirow[t]{2}{*}{3} & 1 & 26,5 & 185 & 43,7 & 1,41 & 1,97 & 1,98 \\
\hline & 2 & 26,8 & 174 & 39,8 & 4,11 & 4,98 & 4,20 \\
\hline \multirow[t]{2}{*}{4} & 1 & 26,7 & 182 & 46,2 & 1,65 & 1,71 & 2,04 \\
\hline & 2 & 27,2 & 170 & 34,3 & 4,31 & 4,41 & 4,82 \\
\hline \multirow[t]{2}{*}{5} & 1 & 26,9 & 185 & 37,4 & 1,56 & 1,79 & 1,89 \\
\hline & 2 & 27,2 & 170 & 45,6 & 4,45 & 5,01 & 4,95 \\
\hline
\end{tabular}

The determined mean total angular deformation resulting from the double fillet weld, recorded in the midlength point of the specimen (Gauge 2), amounted to 2,39 . 


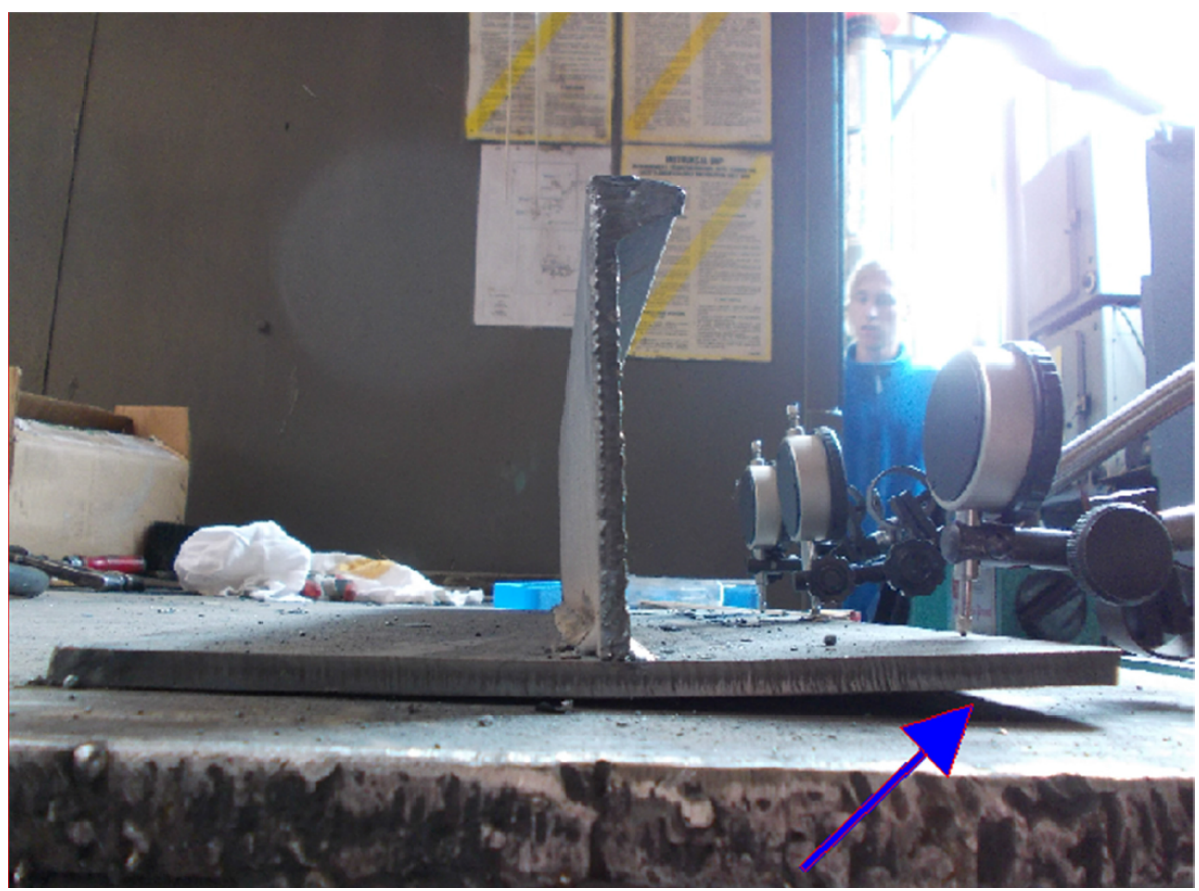

Fig.4. Measurement of angular deformation

\section{ANALYSIS OF ANGULAR DISTORTION BY USING SELECTED ENGINEERING FORMULAS}

\section{Method 1 [12]:}

In this approach it is assumed that angular distortion results from non-uniform distribution of transverse shrinkage of weld itself and its surrounding zone. The distortion is meant to be the deflection angle $\beta$ of the plates (Fig. 5) in relation to their initial position prior to welding and depends on the weld dimension a.
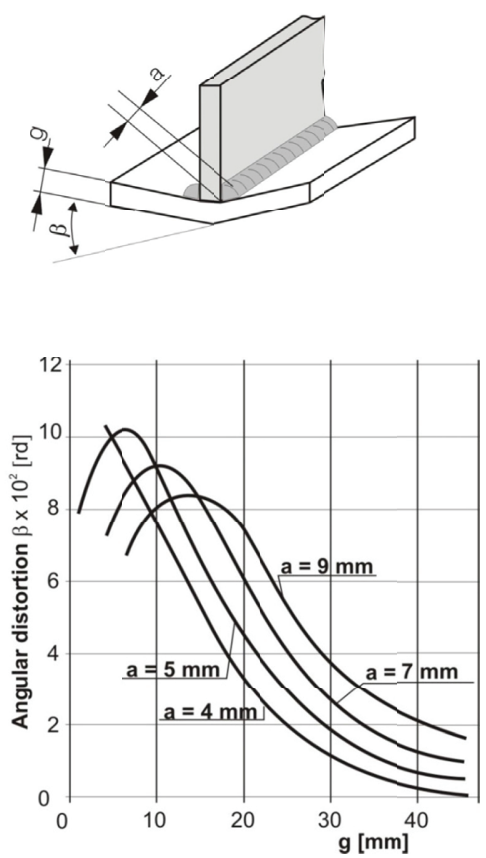

Fig. 5. Nomogram for determining the angular distortion $\beta$ [4]
For the data of the tested specimens the deflection angle determined by using this method, amounts to $\beta=3,30^{\circ}$

Method 2 [11]:

In this method it is assumed that quantity of angular distortions depends first of all on the ratio of the fillet weld thickness a and the flange plate thickness $g$ (Fig. 6). As results from the analysis of the presented indices, in the case of flange plate of a small thickness, e.g. $g=6 \mathrm{~mm}$, the angular distortions are low as temperature gradients across plate thickness are low. The largest angular distortions occur for the flange plate of $8 \div 12 \mathrm{~mm}$ in thickness. Moreover, it can be observed that for the flange plate of a greater thickness the angular distortions decrease.
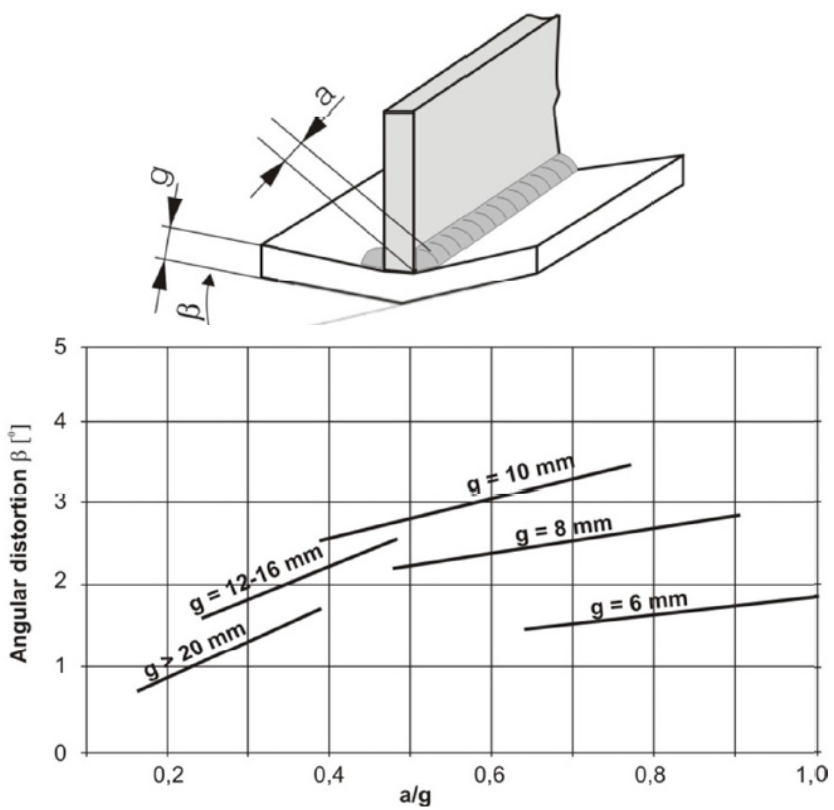

Fig. 6. Data for the plate angular distortion $\beta$ resulting from fillet welds [3] 
For the data of the tested specimens the deflection angle determined by using this method, amounts to $\beta=2,20^{\circ}$

Method 3 [4]:

In this method it is assumed that the angular distortion resulting from a single fillet weld may be determined by using the following formula:

$$
\beta_{0}=0,005\left(14 \frac{a}{g}-1\right)[\mathrm{rad}]
$$

and, for a double fillet weld it may be assumed that the total deflection angle is two times greater:

$$
\beta_{1+2} \cong 2 \beta_{0}
$$
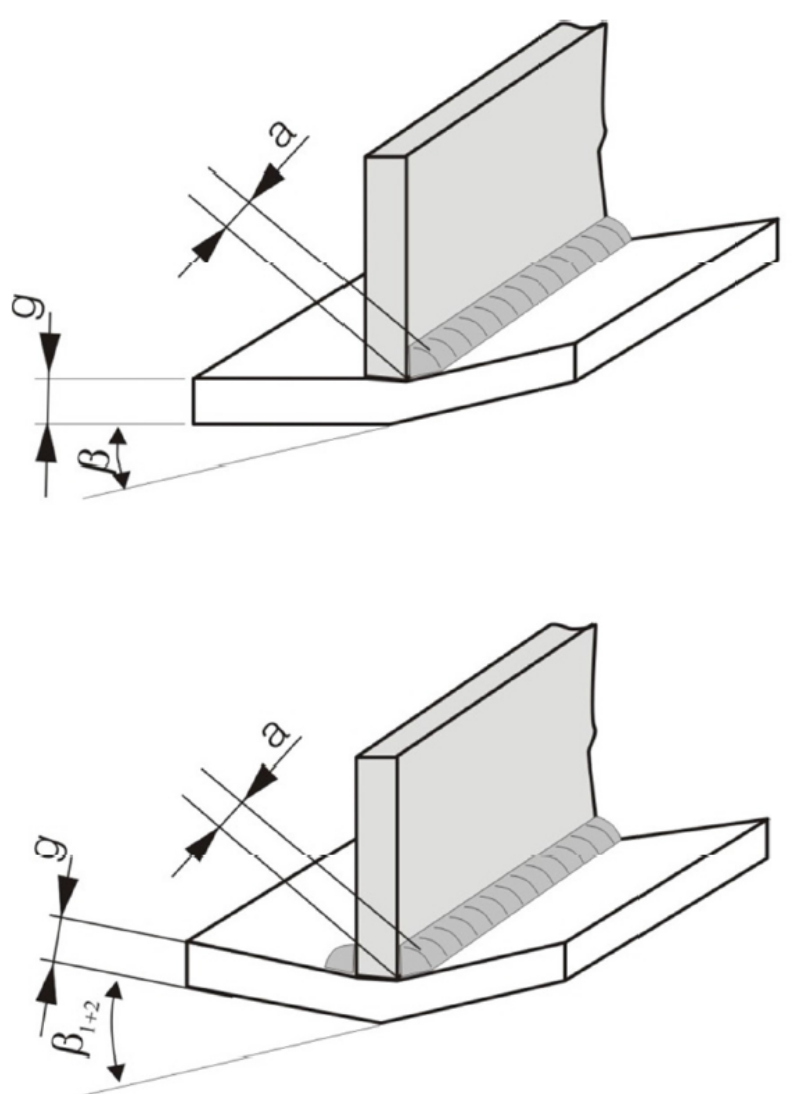

Fig. 7. Definition of the angular distortion according to Method 3 [4]

In case of long welds the angular distortion grows and its extreme value may amount to $\beta_{1+2}=3 \beta_{0}$

For the data of the tested specimens the deflection angle estimated by using this method, amounts to $\beta_{1+2}=2,94^{\circ}$.

\section{Method 4 [2]:}

In this approach it is assumed that the angular distortion results from weld transverse shrinkage (Fig. 8), as well as from surrounding material shrinkage greater than the first one. Occurrence of angular distortion is conditioned by a nonidentical plastic deformation of welded material and weld, observed across thickness .

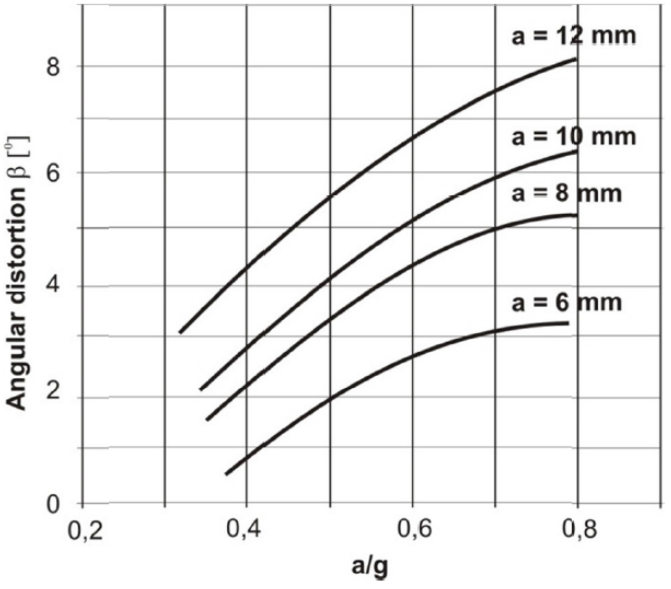

Fig. 8. Indices for estimating the angular distortion resulting from fillet welds [2]

Analytical determination of angular distortion values is not widely used in engineering practice. It results from that it is not possible to take into account, with a sufficient accuracy, many technological factors such as: welding energy, welding method, shape and size of plastic deformation zone, number of runs, plate thickness, weld length, stiffness of welded joint. The formulas met in the literature often provide results which differ from actual ones rather considerably.

The angular distortion value determined for the tested specimen by means of the indices given in Fig. 8, amounts to $\beta=2,75^{\circ}$

\section{Method 5 [5]:}

During T-joint welding the angular distortions are caused by plate's bending due to non-uniform transverse shrinkage across plate thickness as well as by plate's bending resulting from shrinkage of slightly melted metal of weld itself. Fig. 9 presents the mechanism of angular distortion in T-joints.

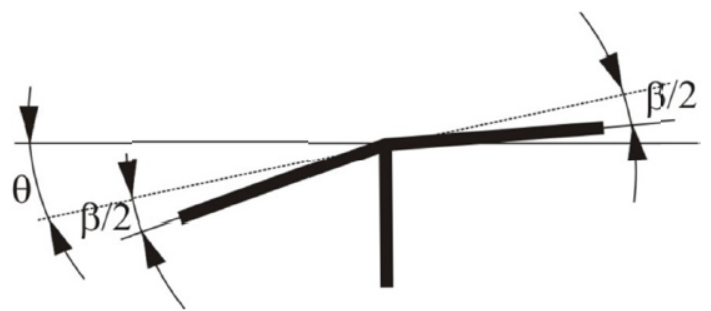

Fig.9. Mechanism of angular distortion in T-joints, assumed in the method in question [5]

During laying the first weld the flange plate will rotate by the angle $\Theta$ in relation to its initial position as a result of weld metal shrinkage. Moreover, as a result of non-uniform transverse shrinkage across flange thickness its bending will occur by the angle $\beta_{1}$ against its initial plane. The angle $\Theta$ only slightly depends on welding parameters and its value may be assumed equal to $0,02 \div 0,024 \mathrm{rad}\left(1,2 \div 1,5^{\circ}\right)$. The angle $\beta_{1}$, if the flange is free to deform, can be determined on the basis of the diagram (nomogram) shown in Fig. 10, where the computational thickness $\mathrm{g}_{0}$ is taken equal to the flange 
a)

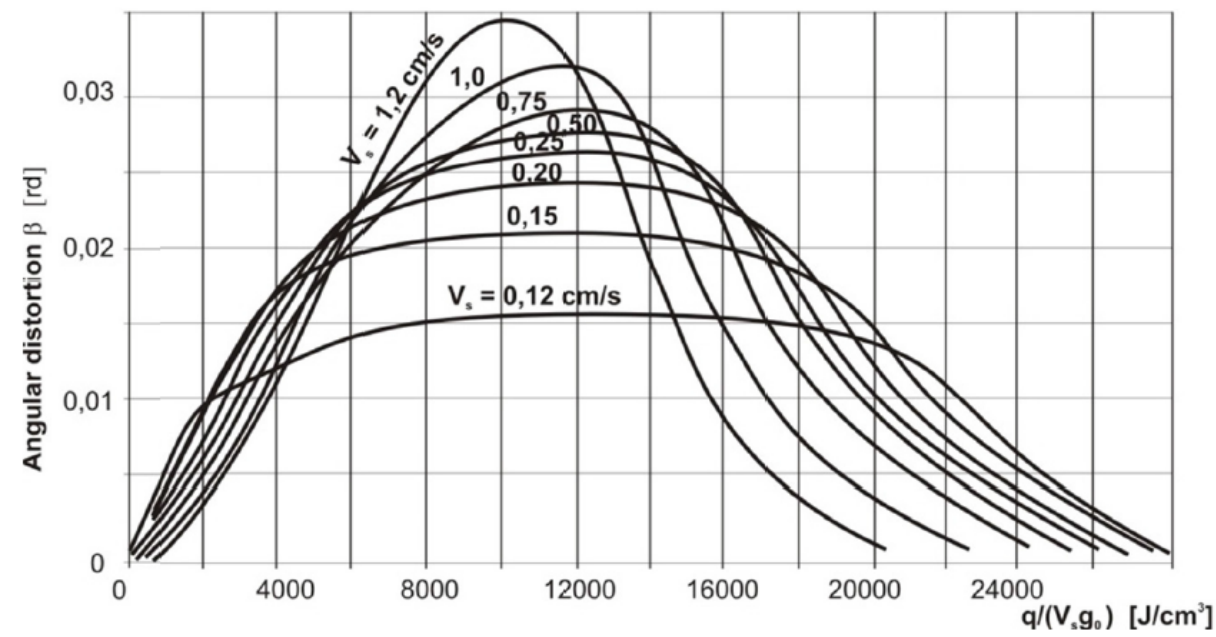

b)

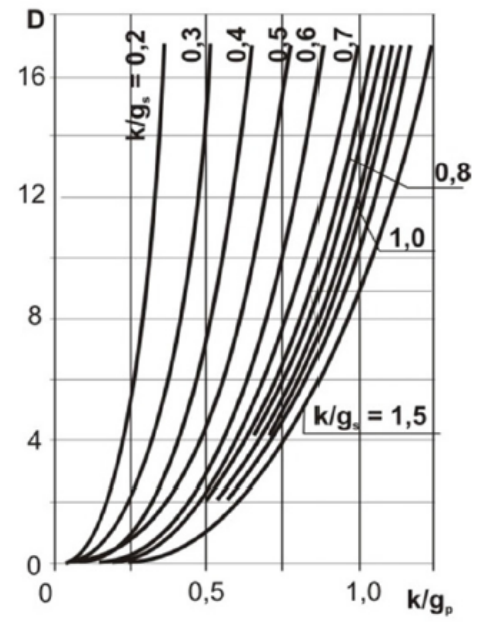

Fig.10. Nomograms: a) for determining the angular distortions $\beta$ during welding butt welds and T-joints in function of the welding conditions $q$, $v_{s}$, and the computational shell plate thickness $\left.q_{0}, b\right)$ for determining the coefficient $D$ [5]

thickness $g_{p}$, and the computational value of linear energy is calculated by means of the following formula:

$$
q_{l_{0}}=q_{l} \frac{2 g_{p}}{2 g_{p} \dashv g_{s}}
$$
$[\mathrm{cm}]$.

where: $g_{p}$ - flange plate thickness $[\mathrm{cm}], g_{s}$ - stiffener thickness

In the case of double welding in T-joint, the plate deflection angle $\beta$ is calculated as follows :

$$
\beta=\beta_{1}+\beta_{2}+\beta_{k}
$$

where: $\beta_{1}$ and $\beta_{2}$, [rad] - plate deflection angles resulting from non-uniform transverse shrinkage in the first and the second weld, respectively; $\beta_{k}[\mathrm{rad}]$ - plate deflection angle due to the double welding of the stiffener, resulting from shrinkage of slightly melted metal during second run.

The angle $\beta_{1}$ and $\beta_{2}$ is determined separately for the weld 1 and 2 by using the nomogram of Fig. 10a in function of welding parameters, thickness of plates and welding speed. The angle $\beta_{k}$ is calculated as follows:

$$
\beta_{k} \approx \varepsilon_{e} D
$$

where: $\mathrm{D}$ - a coefficient dependent on the weld leg $\mathrm{k}$, flange plate thickness $g_{p}$ and stiffener thickness $g_{s}$; its value can be determined from the nomogram of Fig. $10 \mathrm{~b}$; and $\varepsilon_{e}$ - relative deformation ( strain) corresponding to yield strength of weld metal.

For the parameters of the conducted experiment the final angular distortion calculated in compliance with Method 5 is equal to $\beta=2,98^{\circ}$.

\section{COMPARISON OF THE OBTAINED RESULTS}

Analysis of the results of determination of the angular distortion resulting from double fillet weld in $\mathrm{T}$ - joint shows that, except of the approach 2 , the remaining methods provide over-estimated results. Values of the distortions calculated by using the selected algorithms are given in Tab. 3 together with results obtained from the conducted experiment.

Tab. 3 Comparison of the obtained results

\begin{tabular}{|l|c|c|}
\hline \multicolumn{1}{|c|}{ Method } & $\begin{array}{c}\text { Obtained angular } \\
\left.\text { distortion }{ }^{\circ}\right]\end{array}$ & $\begin{array}{c}\text { Deviation from the } \\
\text { mean value from the } \\
\text { experiment [\%] }\end{array}$ \\
\hline No.1 [12] & 3,30 & +38 \\
\hline No. 2 [11] & 2,20 & -8 \\
\hline No. 3 [4] & 2,94 & +23 \\
\hline No. $4[2]$ & 2,75 & +15 \\
\hline No. 5 [5] & 2,98 & +25 \\
\hline $\begin{array}{l}\text { Experiment }(\text { mean } \\
\text { value of 5 tests }\end{array}$ & 2,39 & \\
\hline
\end{tabular}

As can be observed, all the results are comprised within the interval of $2,20 \div 3,30$, hence it may be concluded that on the engineering accuracy level a simplicity and possibility of fast and easy use of a method decide on its practical usefulness. 
The result obtained from the approach 2 , despite its underestimated value, has appeared to be the closest to the mean value achieved from the performed experiment (see Tab. 3).

\section{SUMMARY}

Value of angular distortions in a welded T-joint depends on many parameters, including: weld geometrical dimensions, weld penetration profile, mechanical and physical-chemical properties of material, electric current source. In some cases calculated values of angular distortions greatly differ from those obtained from the experiment. It results from difficulty and in many cases - just from inability of determining the impact of all the factors on value of the distortion. Usually, welding deformations lead to a more complex effect than an angular distortion itself, therefore the values obtained by applying theoretical methods should be considered approximate (rough) ones only.

The most effective method in mitigating welding deformations, apart from straightening, is an appropriate preparation of production process.

\section{BIBLIOGRAPHY}

1. Brzozowska A.: Review and verification of formulas for estimating angular distortions in T-joints (in Polish). Diploma thesis, Faculty of Offshore Engineering and Shipbuilding, Gdańsk University of Technology, 2014

2. Ferenc K., Ferenc J.: Welded structures, Joints (in Polish). Wydawnictwa Naukowo-Techniczne (Publishers), Warszawa , 2000

3. Gourd L.M.: Principles of Welding Technology. The Welding Institute, London, 1995

4. Jakubiec M., Lesiński K. J., Czajkowski H.: Welding of steel structures (in Polish). Wydawnictwo Politechniki Gdańskiej (Publishers), Gdańsk, 1987

5. Jakubiec M., Lesiński K., Czajkowski H.: Technology of welded structures (in Polish). Wydawnictwa NaukowoTechniczne (Publishers), Warszawa 1987

6. Michaleris P., Debiccari A.: Prediction of Welding Distortion, a two-step numerical analysis technique developed to predict welding induced distortion and the structural integrity of large and complex structures. Paper presented at the AWS Annual Convention, April 1996, Chicago, ILL. Welding Research Supplement, April 1997

7. Myśliwiec M.: Thermal - mechanical background of welding technology (in Polish). Wydawnictwa NaukowoTechniczne (Publishers), Warszawa 1972
8. Myśliwiec M.: Welding technology in shipbuilding (in Polish), Wydawnictwo Morskie (Publishers), Gdańsk , 1971

9. O’Brien, Roger William Predicting weld distortion in the design of automotive components. Durham theses, Durham University, 2007, Available at Durham E-Theses Online: http://etheses.dur.ac.uk/2462/

10. Okerblom N. O., Demjancevic V. P., Bajkova I. P.: Proektirovanie technologii izgotovlenija svarnych konstrukcij : rascetnye metody (in Russian).

11. Engineer's handbook : Welding technology, Vol. I (in Polish). Wydawnictwa Naukowo-Techniczne (Publishers), Warszawa, 2003

12. Piwowar S.: Welding technology: Manufacturing techniques (in Polish). Państwowe Wydawnictwo Naukowe (Publishers), Warszawa, 1978

13. Polish Register of Shipping : Rules for the classification and construction of sea-going ships , Part II - Hull (in Polish ), Polski Rejestr Statków (Publishers), Gdańsk, 2015

14. Sędek P.: Problems of welding stresses and deformations (in Polish). Wydawnictwo i dystrybucja: Biuro Gamma (Publishing and disposal), Warszawa , 2000

\section{CONTACT WITH THE AUTHOR}

\author{
Janusz Kozak, \\ Jakub Kowalski \\ Gdańsk University of Technology \\ 11/12 Narutowicza St. \\ 80 - 233 Gdańsk \\ Poland
}

